\section{Prevalência dos marcadores sorológicos dos vírus das hepatites $B$ e $D$ na área indígena Apyterewa, do grupo Parakanã, Pará, Brasil}

\author{
Prevalence of hepatitis B and D serological \\ markers in the Parakanã, Apyterewa Indian \\ Reservation, Pará State, Brazil
}

\footnotetext{
1 Seção de Hepatologia, Instituto Evandro Chagas, Belém, Brasil.

2 Núcleo de Medicina Tropical, Universidade Federal do Pará, Belém, Brasil.

Correspondência H. M. Nunes Seção de Hepatologia, Instituto Evandro Chagas. Av. Almirante Barroso 492 , Belém, $P A$

66090-000, Brasil.

heloisanunes@iec.pa.gov.br
}

\begin{abstract}
In order to study the prevalence of hepatitis $B$ $(H B V)$ and $D(H D V)$ viruses in the Parakanã Indians and to evaluate the impact of hepatitis $B$ vaccination beginning there in 1995, 258 serum samples were analyzed in the year 2004 for hepatitis B and D serological markers using immunoenzymatic techniques; the results showed a moderate endemic pattern, with a total prevalence of HBV infection of $55.7 \%$ and $5.4 \%$ of virus carriers in the Apyterewa village and $49.5 \%$ with $1.1 \%$ of $H B V$ carriers in the Xingu village; $31.4 \%$ of anti$H B s+$ as an isolated marker in both villages and no detection of positive serological tests for HDV among HBV carriers. The laboratory analysis thus showed the presence of chronic HBV carriers, absence of HDV carriers, and an emerging vaccine profile among susceptibles, confirming the effectiveness and need to maintain vaccination, especially in the first year of life, and the need to implement effective epidemiological surveillance for early detection of HDV infection among $H B V$ carriers.
\end{abstract}

Hepatitis B Virus; Hepatitis D Virus; Indian Health; Indian Population
Heloisa Marceliano Nunes 1

Maria Rita de Cassia Costa Monteiro 2

Manoel do Carmo Pereira Soares 1

\section{Introdução}

As infecções pelos vírus das hepatites B (HBV) e D (HDV), objeto deste estudo, representam um sério problema de saúde pública em todo o mundo, sendo esses agentes determinantes importantes de formas graves de doença aguda ou crônica do fígado.

O padrão epidemiológico de prevalência da infecção crônica pelo HBV de uma região tende a ser definido pela prevalência dos marcadores sorológicos HBsAg, anti-HBc e anti-HBs, considerando-se áreas de alta endemicidade aquelas com prevalência acima de $8 \%$ de infecção crônica ou acima de $60 \%$ da população com evidência sorológica de infecção prévia; de endemicidade moderada, aquelas com prevalência de infecção crônica entre $2 \%$ e $7 \%$ ou $20 \%$ a $60 \%$ da população com evidência sorológica de infecção prévia; e, de baixa endemicidade, as regiões com prevalência de infecção crônica menor que $2 \%$ ou menos de $20 \%$ da população com infecção prévia sorologicamente evidenciada 1,2 . No Brasil, são encontrados padrões de baixa endemicidade nas regiões Sul e Sudeste, média endemicidade nas regiões Centro-Oeste e Nordeste e alta endemicidade na Região Amazônica, Espírito Santo e oeste de Santa Catarina 3. Na Amazônia, a endemicidade pelo HBV não é uniforme, existindo áreas de alta e moderada endemicidade mesmo em áreas consideradas de baixa endemicidade 4 . 
A infecção pelo vírus da hepatite D (originalmente agente delta) 5 tem distribuição geográfica heterogênea, estimando-se cerca de 18 milhões de infectados pelo HDV entre os 350 milhões de portadores crônicos do HBV em todo o mundo 6,7.

Desde a década de 1950, estudos realizados entre populações autóctones da América do Sul, principalmente em algumas áreas da Amazônia brasileira, venezuelana, colombiana, peruana e equatoriana, têm relatado alta prevalência de infecção e doença ocasionada pelo HBV e HDV $8,9,10,11,12,13,14,15$. Entre as populações indígenas brasileiras, pesquisas têm demonstrado alta endemicidade da infecção pelo HBV e HDV, com variações quanto à prevalência, à idade e ao modo de aquisição dos vírus 16,17,18,19,20,21,22,23,24,25,26,27.

A transmissão dos vírus B e D, em populações indígenas, ocorre precocemente, principalmente entre crianças de 5 a 12 anos de idade e adultos jovens, provavelmente por transmissão familiar e/ou por contato sexual 19,27,28. Nessas populações, a transmissão vertical, pouco tem contribuído para a disseminação do HDV 22,29,30. Entre os índios, importantes fatores estão envolvidos na transmissão desses vírus: seus costumes, sua constituição genética, a ecologia da região, a forma e tempo de contato com outras populações índias e não índias 17,20,24,31.

O HBV, da família Hepadnaviridae, pode estar presente nos indivíduos infectados sob a forma de partículas filamentosas e esféricas, não infectantes; e partículas de Dane, que medem de 42 a 45 nanômetros (nm), infectantes, elas representam toda a estrutura viral, são formadas por um envelope externo protéico que contém o principal determinante antigênico de superfície, o HBsAg; um core ou nucleocapsídeo constituído pelo antígeno do core do vírus da hepatite $\mathrm{B}$, o HBcAg; pelo antígeno $e$ do HBV, o HBeAg; pelo genoma viral (HBV-DNA) e a sua própria DNApolimerase 1,32 .

O HDV, único representante da família Deltaviridae 33 , é um vírus defectivo, que necessita da presença do HBV para provocar infecção in vivo, apresenta-se sob a forma de partículas esféricas, medindo 35 a 37nm, de composição híbrida revestida externamente pelo HBsAg, contendo, no seu interior, o antígeno do HDV (HDAg) e um genoma constituído por ácido ribonucléico (HDVRNA).

O diagnóstico laboratorial específico da infecção pelo HBV pode ser realizado por testes que pesquisam, no soro, os antígenos $\mathrm{HBsAg}$ e HBeAg e os anticorpos anti-HBs, anti-HBc IgM, anti-HBc total e anti-HBe e por testes moleculares que pesquisam quantitativa e qualitativamente o HBV-DNA. O HBcAg, por tratar-se de um antígeno intracelular insolúvel, não pode ser detectado no soro, podendo ser pesquisado no tecido hepático por imunohistoquímica ${ }^{34}$.

Quanto à hepatite $\mathrm{D}$, tanto na co-infecção (quando suscetíveis infectam-se ao mesmo tempo pelos dois vírus) como na superinfecção (quando portadores do HBV infectam-se pelo HDV), nos casos agudos, a detecção do HDAg pode ocorrer precocemente por curto período de tempo, mas o diagnóstico definitivo se faz pela detecção do anti-HD IgM por técnicas imunoenzimática (ELISA) ou de radioimunoensaio (RIA); nos casos crônicos, o diagnóstico baseia-se na detecção de altos títulos das frações anti-HD IgM ou anti-HD IgG ou pela presença do HDAg no tecido hepático.

A vacina contra a hepatite $B$, desenvolvida a partir do plasma de doadores, foi liberada para uso comercial em 1982 35, entretanto, o difícil controle de segurança em animais, a escassez de matéria-prima, o alto custo de produção e o temor da contaminação da vacina por agentes infecciosos foram determinantes para o desenvolvimento de vacina utilizando a tecnologia de DNA recombinante. No Brasil, a vacina recombinante contra a hepatite B começou a ser aplicada, a partir de 1989, em crianças até dez anos de idade, de 13 municípios do Estado do Amazonas, considerados de alta prevalência para infecções pelo HBV e HDV 36. Somente após 1995, essa vacina foi introduzida no Programa Nacional de Imunizações (PNI), em todo o país 37. Uma vez que não existe vacina para prevenção da infecção pelo HDV, a vacinação contra a hepatite B é eficaz para reduzir a incidência dessa infecção na co-infecção HBV-HDV.

Instituído em 1999, o Subsistema de Atenção à Saúde Indígena, no âmbito do Sistema Único de Saúde (SUS), sob responsabilidade da Fundação Nacional de Saúde (FUNASA), ficou organizado em 34 Distritos Sanitários Especiais Indígenas (DSEI), com postos de atendimento nas aldeias onde atuam Agentes Indígenas de Saúde (AIS) e Agentes Indígenas de Saneamento (AISAN), Pólos-base com equipes multidisciplinares de saúde indígena, Casas do Índio que apóiam as atividades de referência e Conselhos de Saúde locais e distritais 38,39. Órgãos e entidades do Ministério da Saúde com ações relacionadas aos povos indígenas, inclusive o Programa Nacional para Prevenção e Controle das Hepatites Virais (PNHV), deveriam promover e readequar seus planos, programas, projetos e atividades para esses povos 40 .

Embora a vacinação universal contra a hepatite B na população indígena tenha sido preconizada pelo PNI desde 1995, tem-se observado, no laboratório de referência para hepatites virais do 
Instituto Evandro Chagas (IEC), Secretaria de Vigilância em Saúde do Ministério da Saúde (SVS/ MS), a ocorrência de casos de hepatite B comprovados clínica e laboratorialmente em crianças indígenas nascidas após a introdução da vacina, reforçando a necessidade de desenvolver atividades de diagnóstico, controle e prevenção da infecção pelo HBV nessas áreas.

$\mathrm{O}$ presente projeto teve como objetivo pesquisar a prevalência da infecção por HBV e HDV nas comunidades indígenas Apyterewa e Xingu, do grupo Parakanã, comparar a freqüência obtida nessa investigação dos marcadores sorológicos para HBV e HDV com os resultados encontrados em 1995, analisar a resposta imune à vacina contra a hepatite B iniciada nas aldeias Apyterewa e Xingu em 1995 e avaliar, nos portadores do HBV, o estado de replicação viral.

\section{Casuística e métodos}

O estudo foi desenvolvido, entre outubro de 2003 e março de 2005, nas aldeias Apyterewa e Xingu, do grupo Parakanã, com os testes laboratoriais sendo realizados na Seção de Hepatologia, do IEC, em Belém, Pará, Brasil.

O grupo indígena Parakanã, da família lingüística Tupi-Guaraní, habita a Terra Indígena Apyterewa entre os rios Xingu e Tocantins, nos municípios de Altamira e São Félix do Xingu, sudeste do Estado do Pará 41. Organiza-se em grupos domésticos com famílias extensas, casamentos poligâmicos, regra de residência patrilocal (a mulher, pelo casamento, segue o marido), subsistindo da agricultura, caça, pesca e coleta de frutos silvestres. O chefe de cada família tem o comando absoluto sobre os indivíduos que dela fazem parte, e a chefia política faz-se por intermédio dos líderes dos grupos domésticos 42 .

As aldeias Apyterewa (latitude 5³3'21,4”S e longitude $52^{\circ} 40^{\prime} 24,6^{\prime \prime O}$ ) e Xingu (latitude 5³6'23,0”S e longitude 5241'20,5”O), acessíveis a partir da sede do Município de Altamira uma hora e vinte minutos por via aérea ou três dias de viagem por via fluvial, ficam distantes uma da outra cerca de trinta minutos de viagem por via fluvial e são constituídas, atualmente, por uma população de 333 indivíduos com 178 e 155 indígenas, respectivamente, habitando casas de barro ou madeira, cobertas de palha com piso de chão batido. Cada aldeia, possui postos de saúde onde estão lotados técnicos de enfermagem nãoíndios, AIS e AISAN desenvolvendo atividades básicas de saúde e saneamento, inclusive atuando como intérpretes.

Após os contatos com a chefia do DSEI/Altamira e com o Conselho Distrital de Saúde Indíge- na de Altamira sobre a continuidade do inquérito soroepidemiológico iniciado nas aldeias Apyterewa e Xingu em 1995, foram desenvolvidas as seguintes atividades: (a) deslocamento para as aldeias, em setembro de 2004, de equipe composta de médico, técnico de laboratório e auxiliar de enfermagem da Seção de Hepatologia do IEC; (b) reuniões nas aldeias explicando, com a ajuda de intérpretes, o objetivo da viagem e as atividades que seriam desenvolvidas, convidando adultos e crianças, por meio de seus responsáveis, a participarem do estudo; (c) leitura do Termo de Consentimento Livre e Esclarecido e assinatura pelos responsáveis das famílias que desejaram participar da pesquisa, foram incluídos, no estudo, todos os indígenas presentes no período de coleta de dados e amostras nas aldeias e excluídos aqueles que manifestaram vontade de não participar; (d) instalação de laboratórios de campo nas aldeias, com equipamentos (gerador de energia elétrica e centrífuga), insumos e material de consumo, fornecidos pelo IEC; (e) preenchimento de ficha individual de inquérito; (f) coleta de $\pm 8 \mathrm{ml}$ de sangue de cada participante através de punção venosa, sendo as amostras identificadas e centrifugadas, os soros acondicionados em criotubos refrigerados em gelo comum, foram transportados ao IEC e congelados a $-20^{\circ} \mathrm{C}$ até a realização dos exames sorológicos; (g) reunião final nas aldeias informando sobre o encerramento das atividades, sobre os exames que seriam realizados no IEC e o envio dos resultados através do DSEI/Altamira; (h) na Seção de Hepatologia do IEC por técnica imunoenzimática (ELISA), com kits comerciais, os soros foram examinados para a presença de HBsAg, anti-HBc total e antiHBs. Nas amostras HBsAg+, foram efetuadas as pesquisas do $\mathrm{HBeAg}$, anti-HBe e anti-HD total. $\mathrm{O}$ excedente das amostras foi congelado a $-70^{\circ} \mathrm{C}$, ficando sob a responsabilidade do IEC. O antiHBc é o mais eficiente marcador sorológico de infecção pregressa pelo HBV, e o anti-HBs apresenta-se como anticorpo neutralizante, conferindo, em princípio, imunidade natural para a infecção. A presença do HBsAg concomitante ao anti-HBc indica viremia, enquanto que, quando esse marcador é acompanhado pelo anti-HBs, indica recuperação com "clareamento" viral, acrescente-se que a vacinação contra o HBV induz à formação do anti-HBs de forma isolada - perfil vacinal; (i) os dados do censo e os resultados sorológicos foram armazenados em base de dados, e as análises estatísticas conduzidas através dos programas Epi Info 2004 versão 3.3 (Centers for Disease Control and Prevention, Atlanta, Estados Unidos) e Biostat 3.0 (Sociedade Civil Mamirauá, Manaus, Brasil). Foram utilizados testes estatísticos paramétricos da ANOVA de um e dois 
critérios para análise de variância, o teste não paramétrico de Mann-Whitney (teste $u$ ) para duas amostras independentes para comparar a idade e avaliar a resposta imune entre os grupos observados e o teste $t$ para populações relacionadas com amostras pareadas para comparação do sexo. Estabeleceu-se, em 0,05 (5\%), o nível de rejeição da hipótese de nulidade (valor de p <0,05); (j) o relatório foi enviado ao DSEI/Altamira, com os resultados dos exames sorológicos e orientações para acompanhamento dos casos positivos, de acordo com o PNHV e para completar os esquemas vacinais, segundo orientações do PNI.

Todo material utilizado foi descartável, e os rejeitos eliminados fora das aldeias. A investigação beneficiou os participantes pela disponibilidade dos resultados dos exames, permitindo que fossem orientados na adoção de medidas preventivas e encaminhados a tratamento quando necessário, também auxiliou na compreensão da situação vacinal para hepatite B daquela população indígena. Este projeto foi submetido e aprovado pelo Comitê de Ética em Pesquisa (CEP) envolvendo seres humanos do IEC e pelo Conselho Nacional de Ética em Pesquisa (CONEP).

\section{Resultados}

No inquérito, foram incluídos 167 indígenas da aldeia Apyterewa e 91 da aldeia Xingu, num total de 258 indivíduos, correspondendo a 77,5\% da população das duas aldeias. A idade variou de 1 mês a 77 anos, com média e mediana de 19 e 15 anos, na aldeia Apyterewa, e de 1 mês a 74 anos, com média e mediana de idade de 17 e 10 anos, na aldeia Xingu, respectivamente. $\mathrm{Na}$ aldeia Apyterewa, a maior freqüência de faixa etária foi de 40 anos e mais, e a menor, entre 7 e 11 meses; na aldeia Xingu, a maior freqüência foi na faixa de 5 a 9 anos, e a menor, nas crianças dos 7 aos 11 meses. Entre as aldeias foi mínima a diferença de freqüência encontrada entre os sexos (Tabela 1).

A análise das 258 amostras coletadas mostrou prevalência global de 3,9\% (10/258) para o HBsAg+; de 53,5\% (138/258) para o anti-HBc total+/anti-HBs+ e 31,4\% (81/258) para o anti-HBs ${ }^{+}$ isolado. Entre as amostras $\mathrm{HBsAg}^{+}$, foi encontrada prevalência de $20 \%$ para o $\mathrm{HBeAg}^{+}$e $60 \%$ para o anti-HBe ${ }^{+}$. Também foi pesquisado nas amostras $\mathrm{HBsAg}^{+}$, o anti-HD total, o qual foi negativo em todas as amostras examinadas (Tabela 2).

Para comparar a prevalência dos marcadores sorológicos das hepatites B e D na área indígena Apyterewa, encontrada no inquérito soroepidemiológico de 1995, com o estudo atual (2004), foi realizado um levantamento junto ao banco de dados da Seção de Hepatologia do IEC, cujos resultados demonstraram que, entre os inquéritos, não houve significância estatística entre os marcadores sorológicos $\mathrm{HBsAg}^{+}(\mathrm{p}=0,650)$ e anti-HBc total+/anti-HBs+ $(\mathrm{p}=0,879)$, o mesmo não se aplicando a presença isolada do anti-HBs+ que foi estatisticamente significante com $\mathrm{p}=0,000$ (Tabela 2).

No inquérito de 1995, foram detectados portadores do HBV em crianças acima de três anos, com maior prevalência $(14,3 \%)$ na faixa dos 30 aos 39 anos. O anti-HBc total+/anti-HBs ${ }^{+}$mostrava menor prevalência $(0 \%)$ na faixa de 7 a 11 meses e maior $(96,4 \%)$ entre 10 a 14 anos de idade, havia $66,7 \%$ desses anticorpos em menores de seis meses de idade, e a infecção pelo HBV ocorria precocemente a partir do primeiro ano de vida, atingindo 52,9\% das crianças entre 1 a 4 anos. $\mathrm{O}$ marcador sorológico anti-HBs ${ }^{+}$não foi encontrado sob a forma isolada em 1995 (Figura 1).

Em 2004, somente foram detectados portadores de $\mathrm{HBsAg}^{+}$acima de dez anos de idade, mais prevalentes (14\%) na faixa etária de quarenta anos e mais. A menor prevalência de anti-HBc total+/anti-HBs+ (0\%) ocorreu dos 7 a 11 meses e dos 3 a 4 anos, e a maior (92,9\%), entre 30 a 39 anos de idade, foi verificada a presença desses anticorpos em $60 \%$ dos menores de seis meses de idade e infecção pelo HBV a partir do primeiro ano de vida em $4 \%$ das crianças entre 1 e 2 anos de idade. $\mathrm{O}$ anti-HBs ${ }^{+}$isolado foi menos prevalente $(0 \%)$ entre 30 a 39 anos e mais prevalente (90\%) entre crianças de 3 a 4 anos de idade (Figura 2).

Quanto ao sexo, o estudo atual mostrou que, na aldeia Apyterewa, o HBsAg+ foi mais prevalente $(77,8 \%)$ no sexo masculino ( $p=0,028)$, e que, na aldeia Xingu, havia apenas uma única portadora do vírus ( $p=0,000$ ), sendo esses achados estatisticamente significantes. Houve predomínio do anti-HBc total+ para o sexo masculino em ambas as aldeias (Apyterewa $\mathrm{p}=0,022$; Xingu $\mathrm{p}=0,036$ ). $\mathrm{O}$ anti-HBs ${ }^{+}$mostrou-se mais prevalente para o sexo feminino ( $p=0,053)$ na aldeia Apyterewa e para o masculino $(\mathrm{p}=0,121)$ na aldeia Xingu.

O presente estudo (2004) mostrou que $89,5 \%$ do total de participantes, haviam recebido três doses da vacina contra a hepatite $\mathrm{B}$, detectou ausência do esquema completo de vacinação em menores de um ano de idade e $100 \%$ de cobertura vacinal nas faixas etárias de 3 a 4 anos, 10 a 19 e 40 anos e mais. Mostrou que $15,1 \%$ dos participantes haviam viajado nos últimos 12 meses anteriores à entrevista: 22,8\% na aldeia Apyterewa e em $1,1 \%$ na Xingu, que $14 \%$ referiram perfurações, entre esses, $72,2 \%$ dos homens apresentaram perfurações no lábio inferior, e 27,8\% das mu- 
Distribuição da população de estudo por faixa etária, aldeia e sexo. Altamira, Pará, Brasil, 2004.

\begin{tabular}{|c|c|c|c|c|c|c|c|c|c|c|c|c|c|}
\hline \multirow[t]{2}{*}{ Faixa etária } & \multicolumn{3}{|c|}{ Aldeia Apyterewa } & \multicolumn{5}{|c|}{ Aldeia Xingu } & \multicolumn{5}{|c|}{ Total geral } \\
\hline & $\begin{array}{c}\text { Mascu- } \\
\text { lino }\end{array}$ & $\begin{array}{c}\text { Femi- } \\
\text { nino }\end{array}$ & Total & $\%$ & $\begin{array}{c}\text { Mascu- } \\
\text { lino }\end{array}$ & $\begin{array}{c}\text { Femi- } \\
\text { nino }\end{array}$ & Total & $\%$ & $\begin{array}{c}\text { Mascu- } \\
\text { lino }\end{array}$ & $\begin{array}{c}\text { Femi- } \\
\text { nino }\end{array}$ & Total & $\%$ & $\begin{array}{c}\% \\
\text { acumu- } \\
\text { lada }\end{array}$ \\
\hline$<6$ meses & 6 & 2 & 8 & 4,8 & 1 & 1 & 2 & 2,2 & 7 & 3 & 10 & 3,9 & 3,9 \\
\hline 7-11 meses & 2 & - & 2 & 1,2 & - & - & - & 0,0 & 2 & - & 2 & 0,8 & 4,7 \\
\hline $1-2$ anos & 4 & 8 & 12 & 7,2 & 8 & 5 & 13 & 14,3 & 12 & 13 & 25 & 9,7 & 14,3 \\
\hline 3-4 anos & 5 & 7 & 12 & 7,2 & 1 & 7 & 8 & 8,8 & 6 & 14 & 20 & 7,8 & 22,1 \\
\hline 5-9 anos & 6 & 21 & 27 & 16,2 & 10 & 10 & 20 & 22,0 & 16 & 31 & 47 & 18,2 & 40,3 \\
\hline 10-14 anos & 10 & 11 & 21 & 12,6 & 6 & 6 & 12 & 13,2 & 16 & 17 & 33 & 12,8 & 53,1 \\
\hline 15-19 anos & 13 & 8 & 21 & 12,6 & 1 & 3 & 4 & 4,4 & 14 & 11 & 25 & 9,7 & 62,8 \\
\hline 20-29 anos & 12 & 14 & 26 & 15,6 & 5 & 8 & 13 & 14,3 & 17 & 22 & 39 & 15,1 & 77,9 \\
\hline 30-39 anos & 5 & 4 & 9 & 5,4 & 3 & 2 & 5 & 5,5 & 8 & 6 & 14 & 5,4 & 83,3 \\
\hline 40 e mais anos & 16 & 13 & 29 & 17,4 & 8 & 6 & 14 & 15,4 & 24 & 19 & 43 & 16,7 & 100,0 \\
\hline \multirow[t]{2}{*}{ Total } & 79 & 88 & 167 & 100,0 & 43 & 48 & 91 & 100,0 & 122 & 136 & 258 & 100,0 & 100,0 \\
\hline & $(47,3 \%)$ & $(52,7 \%)$ & & & $(47,3 \%)$ & $(52,7 \%)$ & & & & $(47,3 \%)$ & $(52,7 \%)$ & & \\
\hline
\end{tabular}

Tabela 2

Distribuição da prevalência dos marcadores sorológicos dos vírus das hepatites B (HBV) e D (HDV) das aldeias Apyterewa e Xingu, por ano de estudo. Altamira, Pará, Brasil, 1995 e 2004

\begin{tabular}{|c|c|c|c|c|c|c|c|c|}
\hline Ano & Aldeias & $\begin{array}{l}\text { População } \\
\text { examinada }\end{array}$ & $\mathrm{HBsAg}+(\%)$ & $\begin{array}{c}\text { Anti-HBc total+/ } \\
\text { Anti-HBs+ (\%) }\end{array}$ & $\begin{array}{l}\text { Anti-HBs+ } \\
\text { isolado (\%) }\end{array}$ & $\mathrm{HBeAg}+(\%)$ & Anti-HBe+ (\%) & $\begin{array}{c}\text { Anti-HD } \\
\text { total+ (\%) }\end{array}$ \\
\hline \multirow[t]{3}{*}{1995 * } & Apyterewa & 117 & $9(7,7)$ & $75(64,1)$ & $-(0,0)$ & $5(55,6)$ & $4(44,4)$ & $-(0,0)$ \\
\hline & Xingu & 79 & $2(2,5)$ & $62(78,5)$ & $-(0,0)$ & $2(100,0)$ & $-(0,0)$ & $-(0,0)$ \\
\hline & Total & 196 & $11(5,6)$ & $137(69,9)$ & $-(0,0)$ & $7(63,6)$ & $4(36,4)$ & $-(0,0)$ \\
\hline \multirow[t]{3}{*}{2004} & Apyterewa & 167 & $9(5,4)$ & $93(55,7)$ & $45(26,9)$ & $2(22,2)$ & $6(66,7)$ & $-(0,0)$ \\
\hline & Xingu & 91 & $1(1,1)$ & $45(49,5)$ & $36(39,6)$ & $-(0,0)$ & $-(0,0)$ & $-(0,0)$ \\
\hline & Total & 258 & $10(3,9)$ & $138(53,5)$ & $81(31,4)$ & $2(20,0)$ & $6(60,0)$ & $-(0,0)$ \\
\hline
\end{tabular}

* As informações de 1995 foram coletadas utilizando o banco de dados da Seção de Hepatologia, Instituto Evandro Chagas.

lheres, perfurações nas orelhas para utilização de adornos, e que $7 \%$ dos entrevistados, todos homens, costumavam ingerir bebidas alcoólicas de forma esporádica.

Entre os portadores de $\mathrm{HBsAg}^{+}$, as viagens e as perfurações mostraram prevalência global de $40 \%$, e, à exceção de um caso que foi vacinado em 1995, todos os demais portadores do vírus completaram o esquema de vacinação contra a hepatite B entre 2000 e 2004. Entre os anti-HBc total+/ anti-HBs+, as viagens tiveram prevalência global de 21,7\%; as perfurações, $21,1 \%$; uso de bebida alcoólica, 13\%; e 91,3\% eram vacinados contra a hepatite B.

\section{Discussão}

A presente investigação revelou populações jovens, constituídas, em sua maioria, por indígenas abaixo dos vinte anos de idade, originários da própria Terra Indígena Parakanã, demarcada recentemente 41 , demarcação essa que deverá contribuir para reduzir o tráfego de não-índios 
Prevalência de HBsAg+, anti-HBc total+/anti-HBs+ e anti-HBs+, isolado por faixa etária, nas aldeias Apyterewa e Xingu. Altamira, Pará, Brasil, 1995.

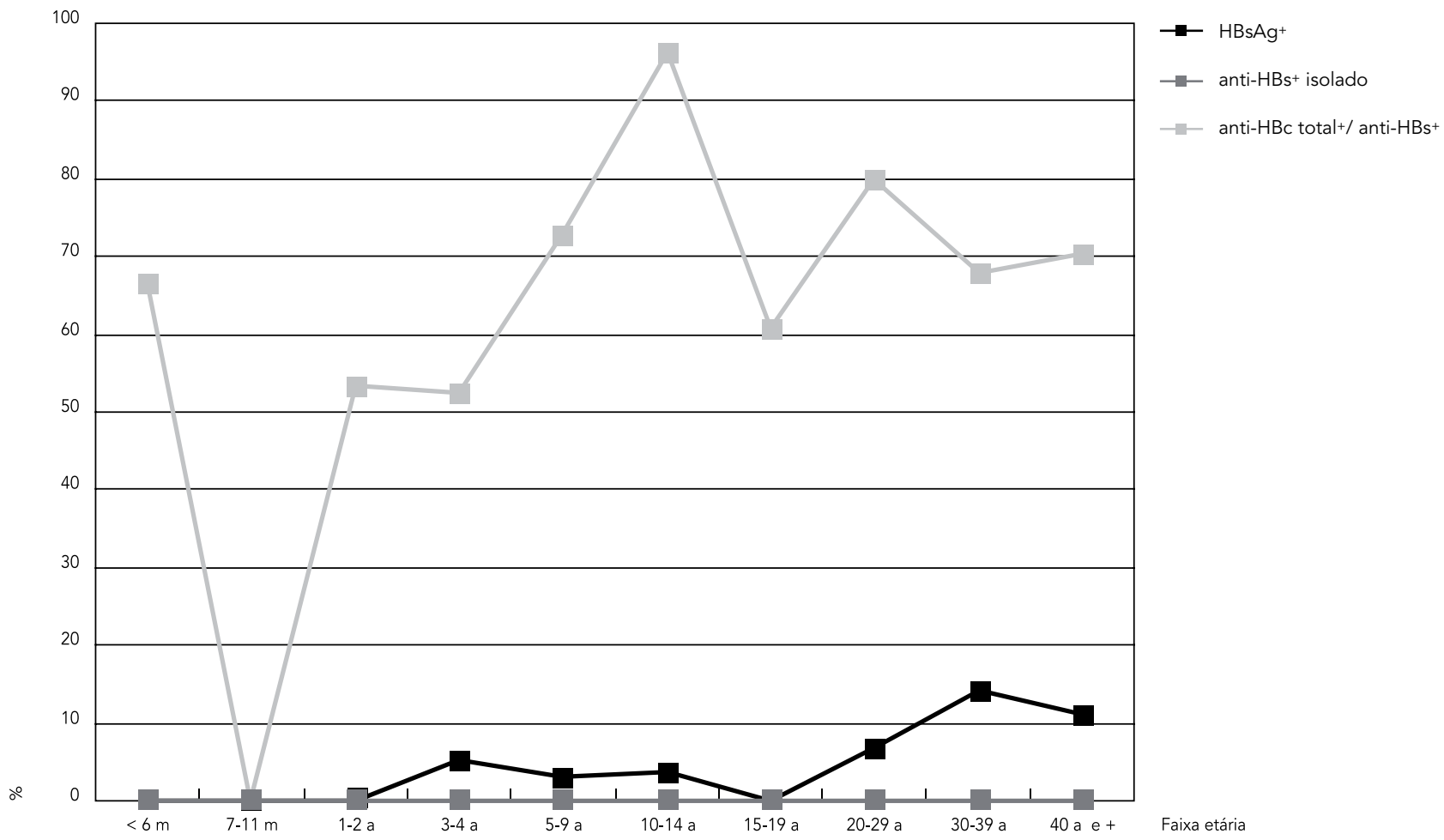

na área. Na aldeia Apyterewa, a maior freqüência de indivíduos acima de quarenta anos e, na Xingu, de crianças dos 5 aos 9 anos demonstrou que a segunda aldeia, construída em local de difícil acesso, nos últimos nove anos, constituiu, de acordo com a regra de residência patrilocal 43 , novos grupos familiares com indivíduos mais jovens, o que vem contribuindo para o aumento de sua população e para a proteção de sua reserva.

O estudo identificou padrão de endemicidade moderada 1,2, com prevalência de infeção pregressa pelo HBV de 55,7\% (anti-HBc total+/antiHBs+), com $5,4 \%$ de portadores do vírus (HBsAg) na aldeia Apyterewa, e de 49,5\% com 1,1\% de portadores, na Xingu. Esse padrão também foi detectado nas tribos Tiriyó, Apalaí, Molokopote, Wayampí, Urubú-Kaapór, Parakanã e Xikrín na bacia Amazônica brasileira e entre os Mapucho, ao sul dos Andes chilenos 17; na comunidade Karitiána, em Rondônia 22 e nas etnias Ikpeng, Awetí, Kuikúru e Mehináku, no Mato Grosso 24.

A freqüência de portadores do $\mathrm{HBV}\left(\mathrm{HBsAg}^{+}\right)$ cinco vezes maior na aldeia Apyterewa em rela- ção à aldeia Xingu classifica a primeira como de moderada endemicidade e a segunda de baixa endemicidade, mostrando a heterogeneidade de prevalência que existe entre elas, mesmo sendo essas, áreas geograficamente próximas e da mesma etnia, semelhantes ao encontrado, em 1994, nas aldeias Paranatinga e Maroxewara, na área indígena Parakanã 28 .

A prevalência de $\mathrm{HBsAg}^{+}$entre os indivíduos acima de dez anos de idade na aldeia Apyterewa e de vinte anos na Xingu demonstrou que a transmissão horizontal tem maior importância que a transmissão vertical nessas populações, à semelhança do encontrado na população indígena Yanomami, no Estado do Amazonas, e entre os Parakanã, no Estado do Pará 28,29. A transmissão sexual parece ser significante nessa população, que conta com indivíduos potencialmente transmissores, em idade sexualmente ativa. Estudo de soroprevalência para a hepatite A e B, em quatro centros no Brasil, que incluiu a Região Norte, verificou "um aumento significativo na soroprevalência para o VHB na adolescên- 
Figura 2

Prevalência de HBsAg+, anti-HBc total+/anti-HBs+ e anti- HBs+, isolado por faixa etária, nas aldeias Apyterewa e Xingu. Altamira, Pará, Brasil, 2004.

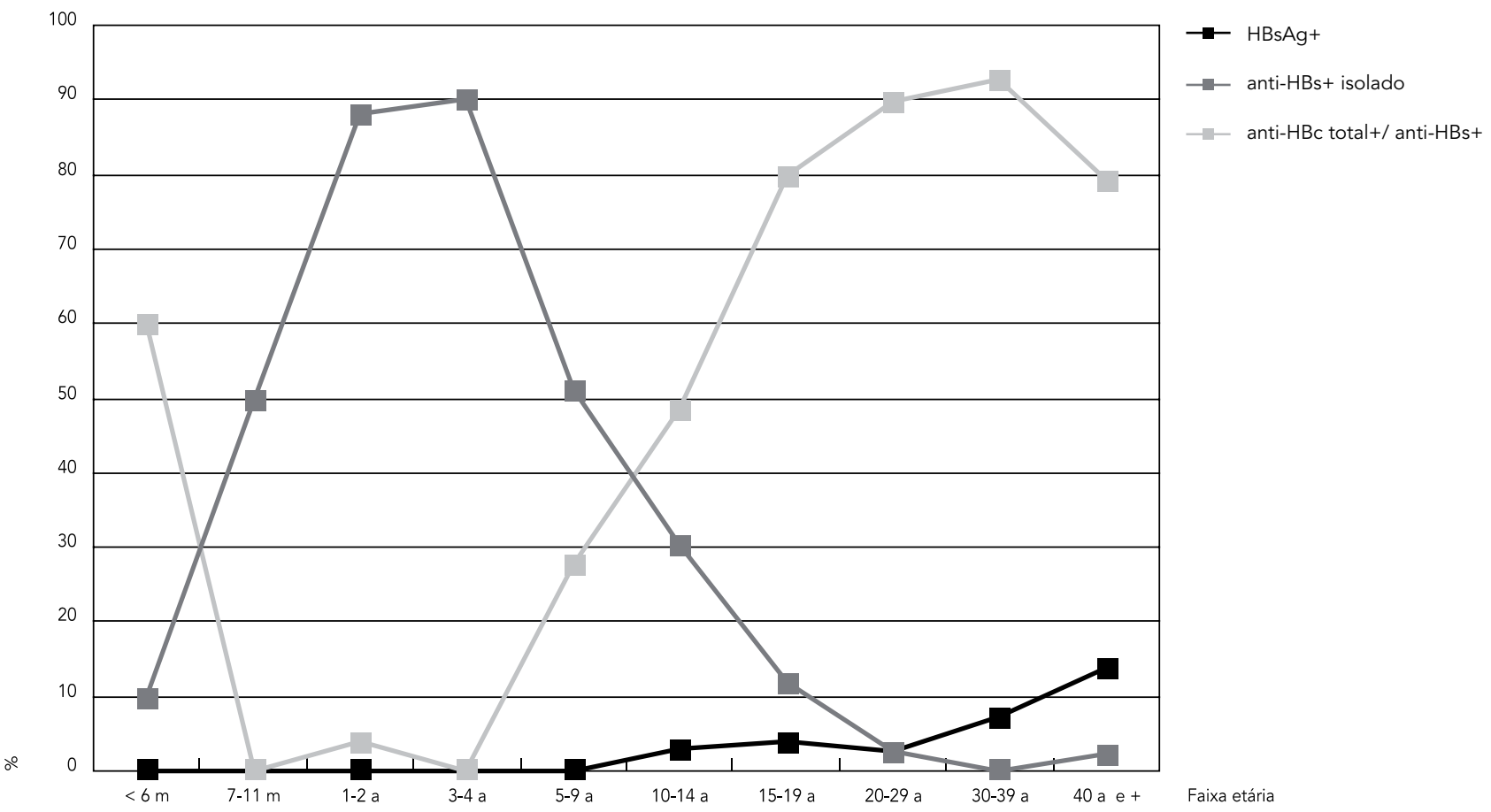

cia, indicando que a atividade sexual é uma significativa via de transmissão deste agente, nesta população" 43 (p. 8).

Embora na população estudada a ocorrência maior seja do sexo feminino, o estado de portador edepreviamenteinfectados peloHBVfoimaisfreqüente no masculino, os homens provavelmente estão mais expostos devido a maior freqüência de viagens para fora da área indígena, às perfurações para utilização de adornos e ao consumo de álcool.

Todos esses achados assemelham-se aos encontrados em outros estudos realizados em populações indígenas da Amazônia brasileira 21,23, é discutível se fatores culturais, sociais, econômicos, genéticos, populacionais, geográficos ou históricos possam ter alguma influência na heterogeneidade encontrada nessas populações.

O estudo comparativo, entre os inquéritos de 1995 e 2004 nas aldeias Apyterewa e Xingu, mostrou que, nos últimos nove anos, houve redução da prevalência global do HBsAg+, redução da prevalência global dos marcadores anti-HBc total+/ anti-HBs ${ }^{+}$e que o anti-HBs ${ }^{+}$, como marcador sorológico isolado, indicando desenvolvimento de imunidade vacinal ao HBV, ausente em 1995, pois a vacinação contra a hepatite B somente foi introduzida nas aldeias a partir daquele inquérito soroepidemiológico, mostrou, em 2004, que houve a emergência de perfil vacinal entre os susceptíveis.

Quando foram comparados os dois inquéritos por faixa etária, percebeu-se que, em 1995, havia portadores de $\mathrm{HBsAg}+$ a partir dos três anos de idade, e a faixa etária de maior prevalência ficava entre 30 e 39 anos. Em 2004, somente havia portadores acima de dez anos de idade, e a maior prevalência foi encontrada em indivíduos acima de quarenta anos, havendo um deslocamento da faixa etária desses portadores do HBV para faixas mais elevadas, com a possibilidade de, em longo prazo, ocorrer a redução dos portadores desse vírus nessas populações, caso medidas de prevenção contra o HBV sejam mantidas nas comunidades. Verificou-se que houve redução da prevalência de anti-HBc total+/anti-HBs+ nos menores de seis meses de idade, aparecimento de susceptíveis e infecção pelo HBV precocemente 
a partir do primeiro ano de vida, embora, a prevalência desses marcadores, entre crianças de 1 a 2 anos em 2004, se mostrasse nitidamente menor que a encontrada em 1995 e redução significativa da prevalência de anti-HBc total+/anti-HBs ${ }^{+}$dos 3 aos 14 anos de idade.

O inquérito de 2004, apesar de detectar o surgimento de perfil vacinal entre os susceptíveis das aldeias Apyterewa e Xingu, revelou baixa prevalência de anti-HBs+ isolado nos menores de um ano de idade, reforçando a necessidade de reavaliar o programa de vacinação contra a hepatite $\mathrm{B}$, nas aldeias investigadas, com o objetivo de melhorar a cobertura vacinal, principalmente entre as crianças menores um ano de idade.

Em 1995, o potencial de replicação e infectividade do HBV era bastante elevado; em 2004, os marcadores $\mathrm{HBeAg}^{+} \mathrm{e}$ anti- $\mathrm{HBe}^{+}$foram detectados apenas na aldeia Apyterewa, em taxas reduzidas demonstrando que existe, embora com baixo potencial, a possibilidade de transmissão do HBV na aldeia.

Os inquéritos não detectaram sorologia positiva para o HDV, admitindo-se que ainda não tenha ocorrido a introdução do vírus nessas aldeias, resultados semelhantes foram encontrados entre os Suyá, Kayabí e Txukahamãe, em Mato Grosso, e nas aldeias Paranatinga e Maroxewara, no Estado do Pará 18,21,27. Estudo em crianças das tribos Caiabi e Txukahamãe, habitantes da região norte do Parque Indígena do Xingu, Estado do Mato Grosso, com características de clima, vegetação e fauna semelhantes às da Região Amazônica, não encontrou sorologia positiva para o HDV em nenhuma das amostras examinadas, mas os pesquisadores tenderam a considerá-la uma região propícia à disseminação do vírus ${ }^{19}$. Pesquisa realizada entre sete grupos indígenas do Estado do Amazonas não detectou a presença de sorologia positiva para o HDV nos Dení, Jamamadí e MúraPirahã, que, apesar de se encontrarem em área de alta endemicidade para a infecção pelo HBV são grupos contatados recentemente e não têm circulação efetiva do HDV 24.

Nas populações investigadas observou-se boa cobertura de vacinação contra a hepatite B, com deficiências entre os menores de um ano de idade, que, sem esquema vacinal completo, mostraram o retardo que existe para o início da vacinação, indo de encontro às orientações do PNI 37, o qual preconiza que a vacinação contra a hepatite B seja iniciada “de preferência logo após o nascimento, nas primeiras 12 horas de vida, para evitar a transmissão vertical" 37 (p. 25).

O hábito de perfurar o lábio inferior para uso de adornos entre adultos do sexo masculino, com "dentes de onças" e de forma compartilhada, freqüente na década de 1980, vem sendo abolido entre os jovens por influência dos não-índios, contribuindo para reduzir o risco de transmissão do HBV nessas populações. Na etnia Xavánte, a perfuração das orelhas fazia parte da iniciação masculina entre rapazes de 12 a 18 anos, prática que, utilizando o mesmo instrumento, geralmente um pedaço afiado de osso de animal, facilitava a transmissão do HBV, numa população com taxa de infecção pelo HBV de 68,3\% 20 .

A vacinação contra a hepatite $B$ não apresentou associação estatística com a presença de portadores do HBV nas aldeias, mas é importante referir que, à exceção de um caso que foi vacinado em 1995, todos os outros portadores do vírus vêm recebendo, sem necessidade, doses complementares da vacina contra o HBV.

Entre os previamente infectados pelo HBV, a presença de perfurações, bebidas alcoólicas e viagens mostrou-se importante como fator de risco. Entre os homens, a prática de perfurar o lábio inferior tende a desaparecer, mas, entre as mulheres, as perfurações nas orelhas são freqüentes. O consumo de bebida alcoólica e as viagens para fora da área indígena, atingindo adolescentes e adultos situados em faixas etárias nas quais o estudo atual detectou aumento de prevalência da infecção pregressa pelo HBV, poderão vir a ser elementos de propagação da infecção pelo HBV nessas aldeias. A vacinação contra a hepatite B não se mostrou significante, porém a detecção de infectados, em crianças em faixa etária com alto risco de evolução para infecção crônica, reforça a necessidade de iniciar, precocemente, a vacinação contra a hepatite B nas aldeias. A presença de infectados, a partir dos cinco anos de idade, em faixa de médio risco para infecção crônica, assemelha-se ao encontrado em outras pesquisas com populações indígenas, as quais demonstraram que a transmissão ocorre, precocemente, por transmissão familiar ou por contato sexual 21,24,27,28.

Os inquéritos detectaram a presença de indivíduos com infecção pregressa pelo HBV e portadores de $\mathrm{HBsAg}^{+}$, mas não puderam determinar quando ocorreu a introdução do vírus nas aldeias, porém aspectos culturais, como a perfuração do lábio inferior nos homens e nas orelhas das mulheres; a infestação por piolhos e o costume de comê-los, comum nas aldeias; as práticas sexuais iniciadas precocemente, às vezes com múltiplos parceiros; a presença de grande quantidade de insetos hematófagos nas aldeias, possibilitando a transmissão mecânica; lesões cutâneas como impetigo, piodermites e escabiose atuando como porta de entrada para o vírus; arranhaduras por galhos e espinhos nas trilhas e matas; o contato familiar com portadores do HBV; o uso comum de objetos e utensílios na alimentação, na higie- 
ne corporal, em tatuagens e rituais, podem ser agentes favorecedores da transmissão do vírus nessas populações 19,20.

\section{Conclusões}

A prevalência dos marcadores sorológicos da hepatite B encontrada, nesta pesquisa, nas aldeias Apyterewa e Xingu, foi de 3,9\% para o $\mathrm{HBsAg}^{+}$, de $53,5 \%$ para o anti-HBc total+/anti-HBs + e $31,4 \%$ para o anti-HBs+ isolado. Entre os $\mathrm{HBsAg}^{+} \mathrm{de}$ ambas as aldeias, os marcadores de replicação e infectividade para o HBV - o HBeAg e anti-HBe foram detectados, mostrando prevalência de $20 \%$ e $60 \%$, respectivamente, e não houve, entre esses, a ocorrência de sorologia positiva para o HDV.

Observou-se, nos últimos nove anos, após a implantação da vacina contra a hepatite B nas aldeias Apyterewa e Xingu, ausência de portadores do HBV entre os menores de dez anos de idade, redução acentuada de infecção prévia pelo HBV na faixa etária de 1 a 14 anos e desvio da infecção pelo HBV para faixas acima dos 15 anos de idade.

\section{Resumo}

Com o objetivo de estudar a prevalência dos vírus das hepatites $B(H B V)$ e D (HDV), nas aldeias Apyterewa e Xingu, do grupo Parakanã, e avaliar o impacto da vacinação contra a hepatite B, iniciada nessas aldeias em 1995, foram coletadas, em 2004, 258 amostras de soro para análise dos marcadores sorológicos das hepatites $B$ e D, por técnicas imunoenzimáticas; cujos resultados revelaram padrão de endemicidade moderada com prevalência total de infecção pelo HBV de 55,7\%, com $5,4 \%$ de portadores do vírus, na aldeia Apyterewa, e de 49,5\%, com 1,1\% de portadores, na Xingu; $31,4 \%$ de anti-HBs ${ }^{+}$como marcador isolado nas duas aldeias, $e$ não foi detectada sorologia positiva para o HDV entre portadores do HBV. Caracterizamos, em base laboratorial, a presença de portadores crônicos do HBV, ausência de portadores do HDV e emergência de perfil vacinal entre os susceptiveis, confirmando a efetividade e a necessidade de manter a vacinação, principalmente no primeiro ano de vida, e, ainda, a necessidade de desenvolver vigilância epidemiológica efetiva para detecção precoce da infecção pelo HDV, entre os portadores do HBV.

Vírus da Hepatite B; Vírus da Hepatite D; Saúde Indígena; População Indígena
A vacinação contra a hepatite B mostrou ser um importante fator de proteção contra o HBV nessas populações, entretanto precisa ser ampliada, principalmente entre os menores de um ano de idade, em ambas as aldeias.

Medidas profiláticas regulares contra o HBV são necessárias para a prevenção da infecção por HBV e HDV, assim como devem ser implantadas medidas de vigilância epidemiológica efetivas, objetivando eventual e precocemente detectar o surgimento do anti-HD entre os indígenas portadores do HBV.

Os achados desta pesquisa parecem indicar a possibilidade de controle dos portadores crônicos do HBV, com redução substancial do número de indígenas infectados nas duas aldeias.

O estudo demonstrou que, nas aldeias Apyterewa e Xingu, a transmissão horizontal familiar tem maior importância que a transmissão vertical, e que a transmissão sexual parece ser significante nessas populações, as quais apresentam características crescentes de infecção relacionadas à idade, contando com indivíduos potencialmente transmissores, em idade sexualmente ativa.

\section{Colaboradores}

H. M. Nunes realizou a pesquisa, elaborou e redigiu o artigo. M. R. C. C. Monteiro e M. C. P. Soares participaram na concepção do projeto, interpretação e discussão dos resultados.

\section{Agradecimentos}

À equipe do Distrito Sanitário Indígena de Altamira, que tornou possível o acesso e a comunicação nas aldeias, e às comunidades indígenas das aldeias Apyterewa e Xingu, que permitiram a realização deste trabalho. 


\section{Referências}

1. Beasley RP, Whang LY. Overview on the epidemiology of hepatocelular carcinoma. In: Hollinger FB, Lemon SM, Margolis HM, editors. Proceedings of the 1990 International Symposium on Viral Hepatitis and Liver Disease. Baltimore: Williams \& Wilkins; 1991. p. 532-5.

2. Souto FJD. Distribuição da hepatite B no Brasil: atualização do mapa epidemiológico e proposições para seu controle. Gastroenterologia e Endoscopia Digestiva 1999; 18:143-50.

3. Fundação Nacional de Saúde. Guia de vigilância epidemiológica. Brasília: Fundação Nacional de Saúde; 2002.

4. Bensabath G, Leão RNQ. Epidemiologia na Amazônia brasileira. In: Focaccia R, organizador. Tratado de hepatites virais. São Paulo: Editora Atheneu; 2003. p. 1-26.

5. Rizzetto M, Canese MG, Arico S, Crivelli O, Trepo $\mathrm{C}$, Bonino F, et al. Immunofluorescence detection of new antigen-antibody system (delta/anti-delta) associated to hepatitis B virus in liver and in serum of HBsAg carriers. Gut 1977; 18:997-1003.

6. Rizzetto M, Shih JW, Gocke DJ, Purcell RH, Verme $\mathrm{G}$, Gerin JL, et al. Incidence and significance of antibodies to delta antigen in hepatitis B virus infection. Lancet 1979; 2:986-90.

7. World Health Organization. Hepatitis B. http:// www.who.int/vaccines-diseases/diseases/hepa titis_b.htm (acessado em 15/Mar/2005).

8. Bensabath G, Dias LB. Hepatite de Lábrea (febre negra de Lábrea) e outras hepatites fulminantes em Sena Madureira, Acre e Boca do Acre, Amazonas, Brasil. Rev Inst Med Trop São Paulo 1983; 25:182-94.

9. Bensabath G, Soares MCP. Febre negra de Lábrea e infecções pelo vírus delta. In: Fundação Serviços de Saúde Pública/Instituto Evandro Chagas, organizadores. Instituto Evandro Chagas: 50 anos de contribuição às ciências biológicas e à medicina tropical. v. 2. Belém: Fundação Serviços de Saúde Pública; 1986. p. 531-89.

10. Bensabath G, Soares MCP, Hadler SC, Fields H, Dias LB, Popper H, et al. Hepatitis delta virus infection and Labrea hepatitis - prevalence and role in fulminant hepatitis in the Amazon Basin. JAMA 1987; 258:479-83.

11. Fonseca JC, Simonetti SR, Schatzmayr HG, Castejon MJ, Cesario AL, Simonetti JP. Prevalence of infection with hepatitis delta virus (HDV) among carriers of hepatitis B surface antigen in Amazonas State, Brazil. Trans R Soc Trop Med Hyg 1988; 82:469-71.

12. Hadler SC, De Monzon M, Ponzetto A, Anzola E, Rivero D, Mondolfi A, et al. Delta virus infection and severe hepatitis. An epidemic in the Yucpa Indians of Venezuela. Ann Intern Med 1984; 100:339-44.

13. Buitrago B, Hadler SC, Popper H, Thung SN, Gerber MA, Purcell RH, et al. Epidemiologic aspects of Santa Marta hepatitis over a 40-year period. Hepatology 1986; 6:1292-6.
14. Casey L, Niro GA, Engle RE, Vega A, Gomez H, McCarthy M, et al. Hepatitis B virus (HBV)/hepatitis D virus (HDV) coinfection in outbreaks of acute hepatitis in the Peruvian Amazon basin: The roles of HDV genotype III and HBV genotype F. J Infect Dis 1996; 174:920-6.

15. Manock SR, Kelley PM, Hyams KC, Douce R, Smalligan RD, Watts DM, et al. An outbreak of fulminant hepatitis delta in the Waorani, an indigenous people of the Amazon basin of Ecuador. Am J Trop Med Hyg 2000; 63:209-13.

16. Black FL, Pandey JP, Capper RA. Hepatitis B epidemiology and its relation to immunogenetic traits in South American Indians. Am J Epidemiol 1986; 123:336-43.

17. Azevedo RA, Silva AEB, Marcopito LF, Baruzzi RG. Prevalência dos marcadores das hepatites A e B em índios do Parque Indígena do Xingu (PIX), Brasil Central. In: XXV Congresso da Sociedade Brasileira de Medicina Tropical. Florianópolis: Sociedade Brasileira de Medicina Tropical; 1989. p. 89.

18. Azevedo RA, Ferraz MLG, Silva AEB, Guimarães RX, Marcopito LF, Baruzzi RG. Sorologia para os vírus de hepatites $\mathrm{B}$, delta e $\mathrm{C}$ em índios de três tribos do Parque Indígena do Xingu, Brasil Central. In: XXVII Congresso da Sociedade Brasileira de Medicina Tropical. Uberaba: Sociedade Brasileira de Medicina Tropical; 1991. p. 154.

19. Azevedo RA, Silva AEB, Ferraz MLG, Marcopito LF, Baruzzi RG. Prevalência dos marcadores sorológicos dos vírus da hepatite B e D em crianças das tribos Caiabi e Txucarramãe do Parque Indígena do Xingu, Brasil Central. Rev Soc Bras Med Trop 1996; 29:431-9.

20. Coimbra Jr. CEA, Santos RV, Flowers NM, Yoshida C, Baptista ML, Valle ACF. Hepatitis B epidemiology and cultural practices in Amerindian populations of Amazonia the Tupi-Mondé and the Xavante from Brazil. Soc Sci Med 1996; 42:1738-43.

21. Instituto Evandro Chagas. Soroepidemiologia das hepatites em comunidades indígenas. In: Instituto Evandro Chagas, organizador. Relatório qüinqüenal 1991/1995. Belém: Instituto Evandro Chagas; 1996. p. 119-22.

22. Ferrari JO, Ferreira MU, Tanaka A, Mizokami M. The seroprevalence of hepatitis B and C in an Amerindian population in the southwestern Brazilian Amazon. Rev Soc Bras Med Trop 1999; 32:299-302.

23. Grajcer B. Prevalência da infecção pelo vírus da hepatite $\mathrm{B}$ e resposta imune à vacina recombinante contra hepatite $B$ com esquema adaptado em população menor de 15 anos do Alto Xingu, 2001 [Dissertação de Mestrado]. São Paulo: Escola Paulista de Medicina, Universidade Federal de São Paulo; 2001.

24. Braga WSM, Brasil LM, Souza RAB, Castilho MC, Fonseca JC. Ocorrência da infecção pelo vírus da hepatite B (VHB) e delta (VHD) em sete grupos indígenas do Estado do Amazonas. Rev Soc Bras Med Trop 2001; 34:349-55. 
25. Black FL, Hierholzer WJ, Pinheiro F, Evans AS, Woodall JP, Opton EM, et al. Evidence for persistence of infectious agents in isolated human populations. Am J Epidemiol 1974; 100:230-50.

26. Soares MCP, Bensabath G. Tribos indígenas da Amazônia Oriental como população de risco para hepatite D (delta). Rev Inst Med Trop São Paulo 1991; 33:241-2.

27. Soares MCP, Menezes RC, Martins SJ, Bensabath G. Epidemiologia dos vírus das hepatites B, C e D na tribo indígena Parakanã, Amazônia Oriental Brasileira. Bol Oficina Sanit Panam 1994; 117:124-35.

28. Castro EJ, Rosa Filho SM. Prevalência dos marcadores dos vírus B e Delta em população indígena da Tribo Yanomami (AM). Mod Hepatol 1989; 1:21.

29. Brasil LM, Braga WSM, Botelho R, Castilho MC, Fonseca JCF. The prevalence of hepatitis $\mathrm{B}$ virus (HBV) markers within household in the state of Amazonas, Brazil. Hepatology 1994; 19:45.

30. Niro GA, Casey JL, Gravinese E, Garrubba M, Conoscitore P, Sagnelli E, et al. Intrafamilial transmission of hepatitis delta virus: molecular evidence. J Hepatol 1999; 30:564-9.

31. Quintero A, Uzcategui N, Loureiro CL, Villegas L, Illarramendi X, Guevara ME, et al. Hepatitis delta virus genotypes I and III circulate associated with hepatitis B virus genotype $\mathrm{F}$ in Venezuela. J Med Virol 2001; 64:356-9.

32. Hoofnagle JH. Serologic markers of hepatitis B virus infection. Annu Rev Med 1981; 32:1-11.

33. Gerin JL. The taxonomy of hepatitis delta virus. In: Nishioka K, Suzuki H, Mishiro S, Oda T, editors. Viral hepatitis and liver disease. Tokyo: Springer-Verlag; 1994. p. 63-4.

34. Burrell CJ. Serological markers of hepatitis B infection. Clin Gastroenterol 1980; 9:47-63.
35. Hilleman MR, Buynak EB, Roehm RR, Tytell AA Bertland AU, Lampson GP. Purified and inactivated human hepatitis B vaccine: progress report. Am J Med Sci 1975; 270:401-4.

36. Bensabath G, Soares MCP. A evolução do conhecimento sobre as hepatites virais na região amazônica: da epidemiologia e etiologia à prevenção. Rev Soc Bras Med Trop 2004; 37 Suppl 2:14-26.

37. Coordenação do Programa Nacional de Imunizações, Centro Nacional de Epidemiologia, Fundação Nacional de Saúde. Manual de normas de vacinação. Brasília: Fundação Nacional de Saúde; 2001.

38. Fundação Nacional de Saúde. Saúde indígena. http://www.funasa.gov.br (acessado em 11/Ago/ 2004).

39. Ministério da Saúde. Portaria GM nº. 254/2002. Aprova a Política Nacional de Atenção à Saúde dos Povos Indígenas. http://www.funasa.gov.br/legis/ pdfs/portarias (acessado em 15/Mai/2003).

40. Ministério da Saúde. Portaria GM nº 70/2004. Aprova as diretrizes da gestão de política nacional de atenção à saúde indígena. http://www.funasa. gov.br/Web\%20Funasa/Legis/pdfs/portarias_m/ pm_70_2004.pdf (acessado em 11/Ago/2004).

41. Ministério da Justiça. Portaria no. 1192. Declara a posse permanente do grupo indígena Parakanã a Terra Indígena Apyterewa. Diário Oficial da União 2002; 4 jan.

42. Magalhães AC, Sassi I. Parakanã. In: Ricardo CA, organizador. Povos indígenas no Brasil - sudeste do Pará (Tocantins). São Paulo: Centro Ecumênico de Documentação e Informação; 1985. p. 18-52.

43. Clemens SAC, Fonseca JC, Azevedo T, Cavalcanti A, Silveira TR, Castilho MC, et al. Soroprevalência para hepatite A e hepatite B em quatro centros no Brasil. Rev Soc Bras Med Trop 2000; 33:1-10.

Recebido em 23/Fev/2006

Versão final reapresentada em 19/Mar/2007

Aprovado em 20/Mar/2007 